\title{
Experimental study on the room temperature uniformity with air supply and back patterns
}

\author{
Hongmei $\mathrm{Wu}^{1, \mathrm{a}^{*}}$, Yong Zhang ${ }^{2, \mathrm{~b}}$, Xin Wang ${ }^{1, \mathrm{c}}$ and Rong Zhou ${ }^{1, \mathrm{a}}$ \\ ${ }^{1}$ China Ship Development and Design Center, Wuhan, China \\ ${ }^{2}$ Huawei Technologies CO., LTD, Shenzhen, China \\ ${ }^{3}$ China Ship Development and Design Center, Wuhan, China \\ ${ }^{4}$ China Ship Development and Design Center, Wuhan, China \\ azhaowuhongmei@163.com, bzhangyongZ@huawei.com,
}

Keywords: Airflow pattern; Temperature uniformity; Nonuniformity coefficient

Abstract. To study the influence of the air supply-return methods and air supply temperature on the temperature uniformity, several scaled experiments were carried. By comparing of the ceiling hole-board ventilation and diffuser air supply, it is shown that the air supply method of ceiling hole-board with air-in and floor air-back is a better airflow pattern.

\section{Introduction}

Air distribution is one of the most important segments during air conditioning system design. Air distribution design of the air conditioner room will directly affect the air conditioning result and energy consumption of air conditioning system. Among all the influencing factors to air distribution, the selection of blowing and return air type or blowing air parameter setting are the most important one. During air conditioner design, the air distribution type has important affection to whole air conditioning result of cabin. Reasonable air distribution can not only improve the air quality in the cabin, but also avoid energy lost, so as to running the air conditioner with low cost. So the prediction and analysis for cabin air distribution is the most important segment in the whole air conditioning design.

This paper talks about the experiment research of uniformity affection to room temperature field under different blowing and return air or different blowing temperature from air conditioner, by utilizing existing device and condition based on the built man-made environment chamber platform.

\section{Experiments}

\section{Experiments Set}

Full scaled experiments were carried out in a lab with several scenarios using a typical room geometry. The dimension of the room considered was $4.8 \mathrm{~m}(\mathrm{x}) \times 3.3 \mathrm{~m}(\mathrm{y}) \times 2.4 \mathrm{~m}$ high $(\mathrm{z})$. Five thermocouple trees were located as shown in figure 1, with five points in each thermocouple tree. And the measured points in vertical dimension were set as shown in figure 2 . An electric stove with $800 \mathrm{~W}$ heat was simulated as the heat gain of the room shown in figure 3-6. Agilent 34970A was used to collect the data. 


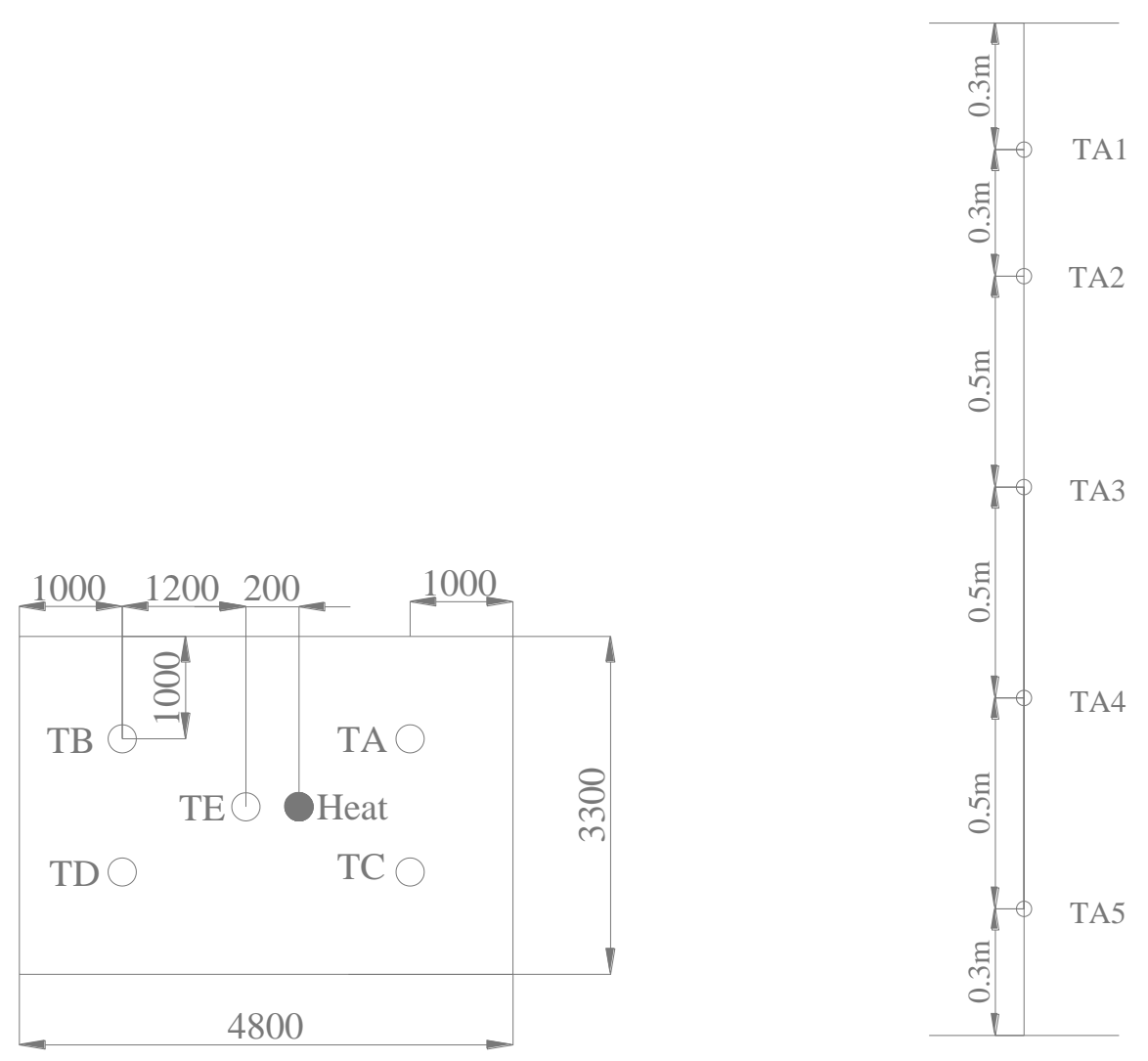

Fig. 1 Layout of the thermocouple trees location Fig. 2 Layout of the thermocouple trees in verticaldirection

\section{Cases and Results}

Three working conditions were set with room temperature $19{ }^{\circ} \mathrm{C}, 17{ }^{\circ} \mathrm{C}$ and $18{ }^{\circ} \mathrm{C}$ separately, and called working condition I, working condition II and working condition III. During the experiments, the air conditioning system was started to make the environmental chamber to working condition I. After working condition I became stable, and then regulated the condition system to get working condition II. After working condition II became stable, opened the window for a while, and then closed it. After working condition II became stable again, increase the room temperature to working condition III. After the working condition III became stable, the experiment was finished. Recorded the temperature of each characteristic point, and then the temperature variation curve during experiment were achieved.

The four experimental cases of airflow patterns were shown in figure 3-6.

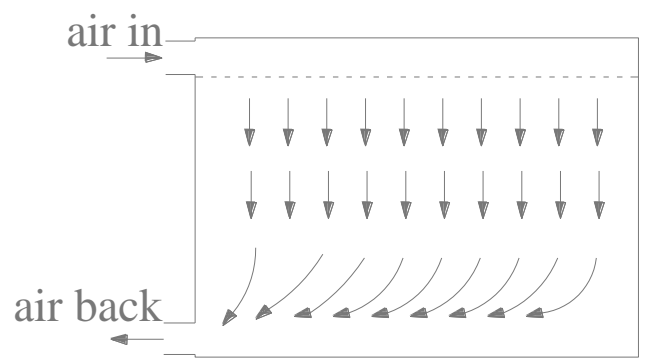

Fig. 3 Case 1- Ceiling hole-board ventilation with ceiling-in and side-back 


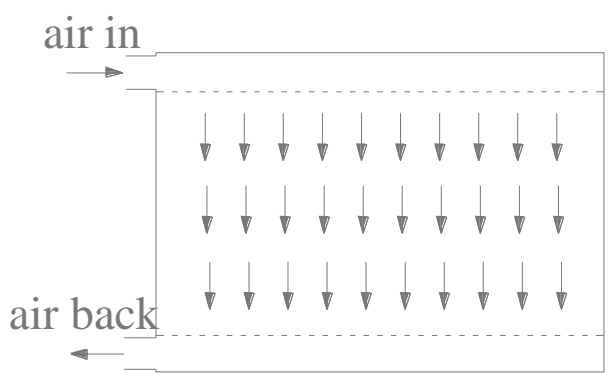

Fig. 4 Case 2- Ceiling hole-board ventilation with ceiling-in and floor-back

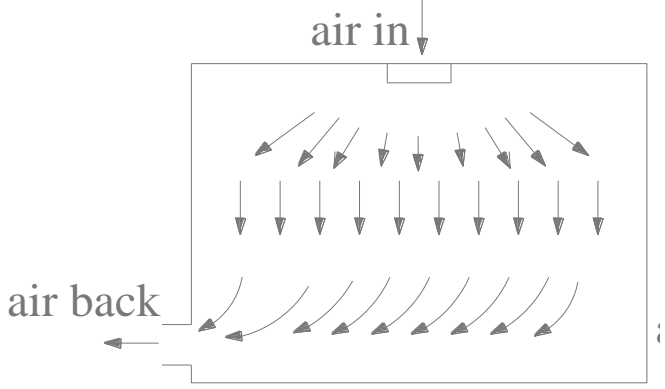

Fig. 5 Case 3- Diffuser air supply with ceiling-in and side-back

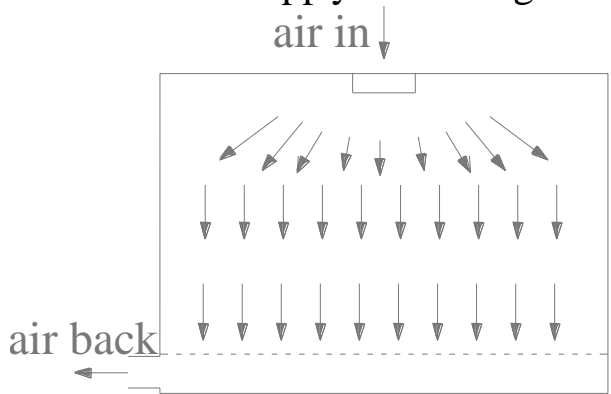

Fig. 6 Case 4- Diffuser air supply with ceiling-in and floor-back

To show the analysis, only the results with case 1 in working condition III were listed in table 1.

Table 1 Results with case 1 in working condition III

\begin{tabular}{llll}
\hline Number & Temperature $\left[{ }^{\circ} \mathrm{C}\right]$ & Number & Temperature $\left[{ }^{\circ} \mathrm{C}\right]$ \\
\hline TA1 & 18.70 & TB1 & 18.48 \\
TA2 & 18.52 & TB2 & 18.59 \\
TA3 & 18.39 & TB3 & 18.73 \\
TA4 & 18.45 & TB4 & 19.22 \\
TA5 & 18.45 & TB5 & 18.37 \\
TC1 & 18.38 & TD1 & 18.44 \\
TC2 & 18.37 & TD2 & 18.54 \\
TC3 & 18.24 & TD3 & 18.89 \\
TC4 & 18.11 & TD4 & 19.11 \\
TC5 & 18.32 & TD5 & 18.63 \\
TE1 & 18.41 & & \\
TE1 & 18.37 & & \\
TE3 & 18.71 & & \\
TE4 & 19.55 & & \\
TE5 & 29.59 & & \\
\hline
\end{tabular}




\section{Analysis}

In the room, temperature differences appear in different locations. And the differences could be evaluated by using the temperature nonuniform coefficient. Several measured points are selected to get the temperature, and then arithmetic mean value is defined in equation 1 :

$$
\bar{t}=\frac{\sum t_{i}}{n}
$$

Where $t_{i}=$ the temperature value, $n=$ the number;

The root mean square deviation is defined in equation 2 :

$$
\sigma_{\mathrm{t}}=\sqrt{\frac{\sum\left(t_{i}-\bar{t}\right)^{2}}{n}}
$$

Then, the temperature nonuniform coefficient $k_{\mathrm{t}}$ is obtained in equation 3 :

$$
k_{\mathrm{t}}=\frac{\sigma_{\mathrm{t}}}{\bar{t}}
$$

Where $k_{\mathrm{t}}$ is a dimensionless number, a smaller value indicates a better air uniformity.

According to the results in table 1 , the nonuniform coefficient $k_{\mathrm{t}}$ was gained with case 1 in working condition III. In the same way, the results of other cases in different working conditions were gained in tables 2-4.

Table $2 k_{t}$ in working condition I

\begin{tabular}{lcc}
\hline \multirow{2}{*}{ Cases } & \multicolumn{2}{c}{ Working condition I } \\
\cline { 2 - 3 } & Temperature difference $\left[{ }^{\circ} \mathrm{C}\right]$ & $k_{\mathrm{t}}$ \\
\hline Case 1 & 0.70 & 0.0166 \\
Case 2 & 0.36 & 0.0141 \\
Case 3 & 0.15 & 0.0163 \\
Case 4 & -0.12 & 0.0146 \\
\hline
\end{tabular}

Table $3 k_{\mathrm{t}}$ in working condition II

\begin{tabular}{lcc}
\hline \multirow{2}{*}{ Cases } & \multicolumn{3}{c}{ Working condition II } \\
\cline { 2 - 3 } & Temperature difference $\left[{ }^{\circ} \mathrm{C}\right]$ & $k_{\mathrm{t}}$ \\
\hline Case 1 & 0.47 & 0.0179 \\
Case 2 & 0.32 & 0.0173 \\
Case 3 & 0.38 & 0.0218 \\
Case 4 & 0.14 & 0.0209 \\
\hline
\end{tabular}

Table $4 k_{\mathrm{t}}$ in working condition III

\begin{tabular}{lcc}
\hline \multirow{2}{*}{ Cases } & \multicolumn{2}{c}{ Working condition III } \\
\cline { 2 - 3 } & Temperature difference $\left[{ }^{\circ} \mathrm{C}\right]$ & $k_{\mathrm{t}}$ \\
\hline Case 1 & 0.58 & 0.0174 \\
Case 2 & 0.34 & 0.0158 \\
Case 3 & 0.37 & 0.0175 \\
Case 4 & -0.08 & 0.0173 \\
\hline
\end{tabular}


Now, the difference of the measured temperature and the set temperature in specific working condition was varied with the set temperature in figure 7 . The comparisons could be obviously illustrated in figure 8 .

From figure 7 and figure 8, it is observed that in hole-board ventilation, the temperature difference increased with the increasing of the room temperature. However, under the condition of air diffuser blowing, the temperature difference decreased with the increasing of the room temperature.

For each case, the nonuniform coefficient was increasing with the decreasing of the room temperature. It is because that the heat convection between the hot air in the room and the cold air from outside makes the temperature field unbalanced when the door was opened at $17^{\circ} \mathrm{C}$.

The nonuniform coefficient in Case 2 is less than other cases at different situations. A conclusion was drawn that a good temperature uniform was made with the ceiling hole-board air in and the floor air back. It could be explained that the blowing speed of hole-board is well-distributed and quick-decayed; also the airflow is blown from top to bottom in a straight-line way, which will not cause irregular turbulence. So the temperature field is well distributed when the airflow is blown from the holeboard at top and returned from the floor at bottom. Overall, the temperature filed uniformity of hole-board ventilation is better than air diffuser blowing, and the temperature filed uniformity of floor return mode is better than side return mode.

Air supply temperature is another factor to affect the temperature field uniform. Several comparisons were done as seen in table 5 .

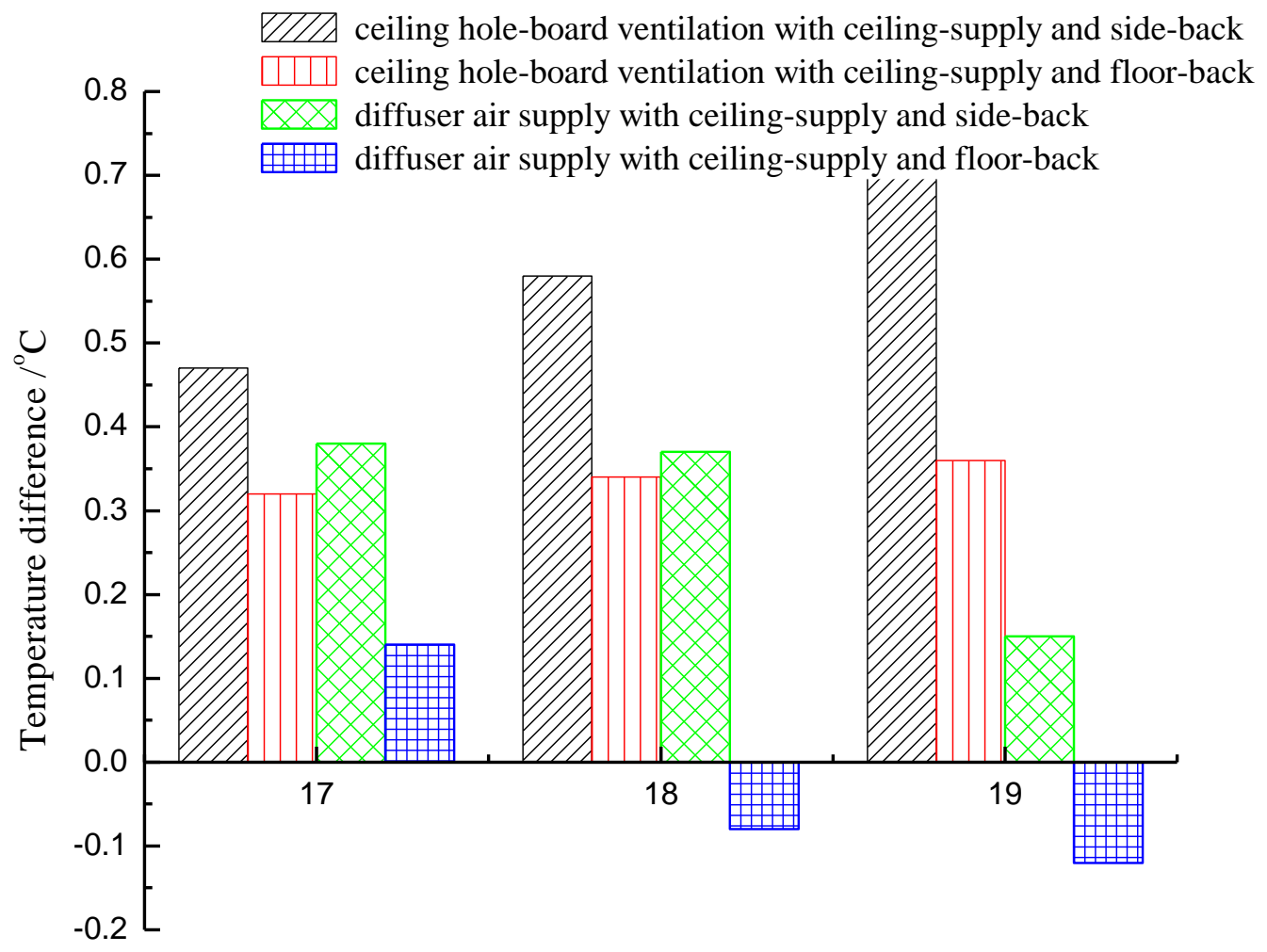

Temperature set $/{ }^{\circ} \mathrm{C}$

Fig. 7 Temperature difference in cases 1-4 


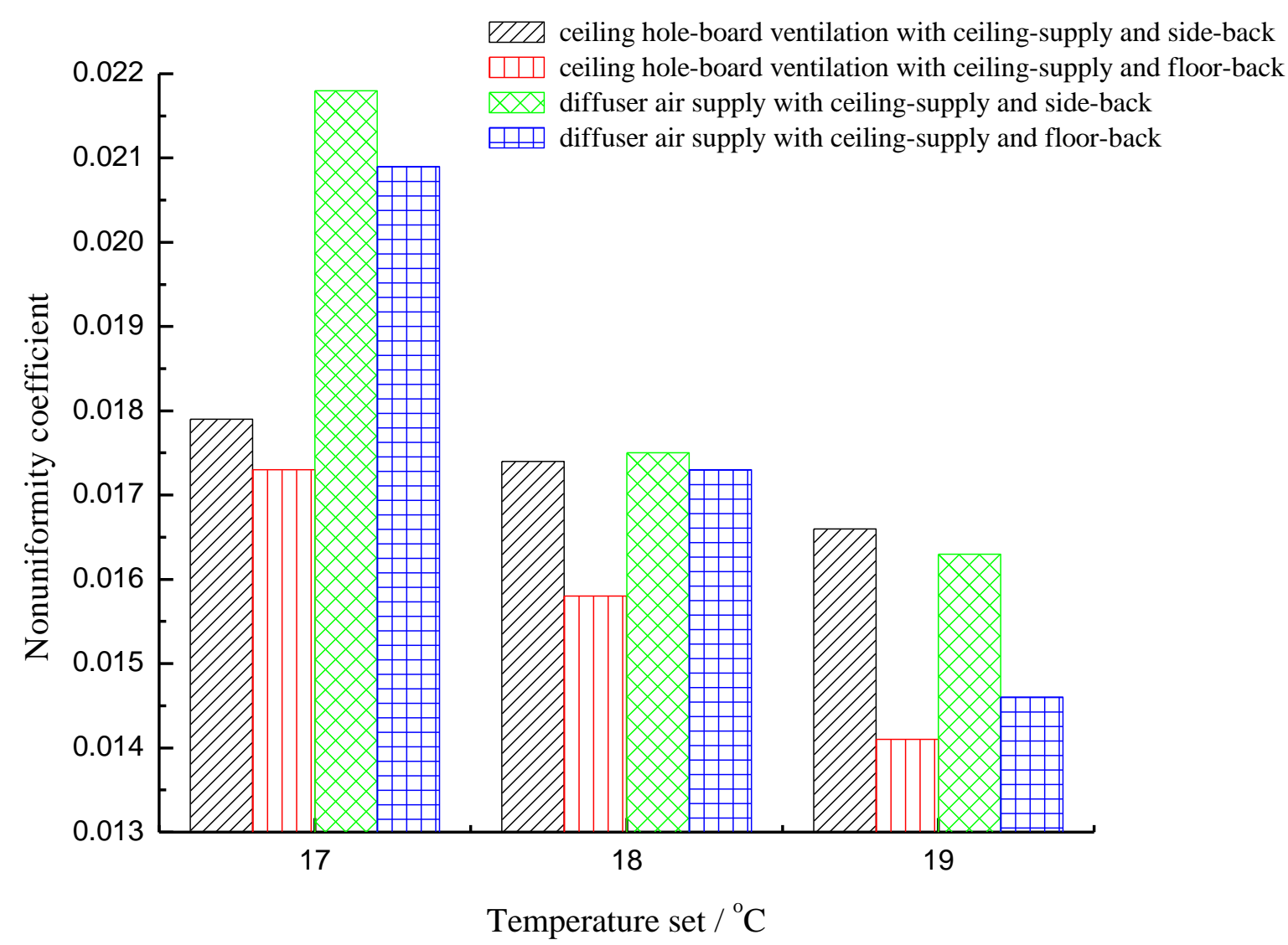

Fig. 8 Nonuniform coefficient in cases 1-4

Table $5 k_{\mathrm{t}}$ in different air supply temperature

\begin{tabular}{lccc}
\hline \multirow{2}{*}{ Case } & \multicolumn{3}{c}{ Air supply temperature } \\
\cline { 2 - 4 } & $12\left[{ }^{\circ} \mathrm{C}\right]$ & $14\left[{ }^{\circ} \mathrm{C}\right]$ & $16\left[{ }^{\circ} \mathrm{C}\right]$ \\
\hline Case 1 & 0.0123 & 0.0116 & 0.0095 \\
Case 2 & 0.0121 & 0.0115 & 0.0091 \\
Case 3 & 0.0136 & 0.0124 & 0.0114 \\
Case 4 & 0.0129 & 0.0118 & 0.0109 \\
\hline
\end{tabular}

Fromfigure 9 it was demonstrated obviously that the temperature nonuniform coefficient with hole-board ventilation is less than air diffuser blowing at the same air supply temperature. And the airflow with ceiling-supply and floor-back is much better than the ceiling-supply and side-back due to a smaller nonuniform coefficient. This result also expresses the temperature field of hole-board is better distributed than air diffuser blowing. In view of air distribution, the temperature filed of supply in the top and return from the bottom mode is better distributed than the ventilation from the top and return from the bottom. 


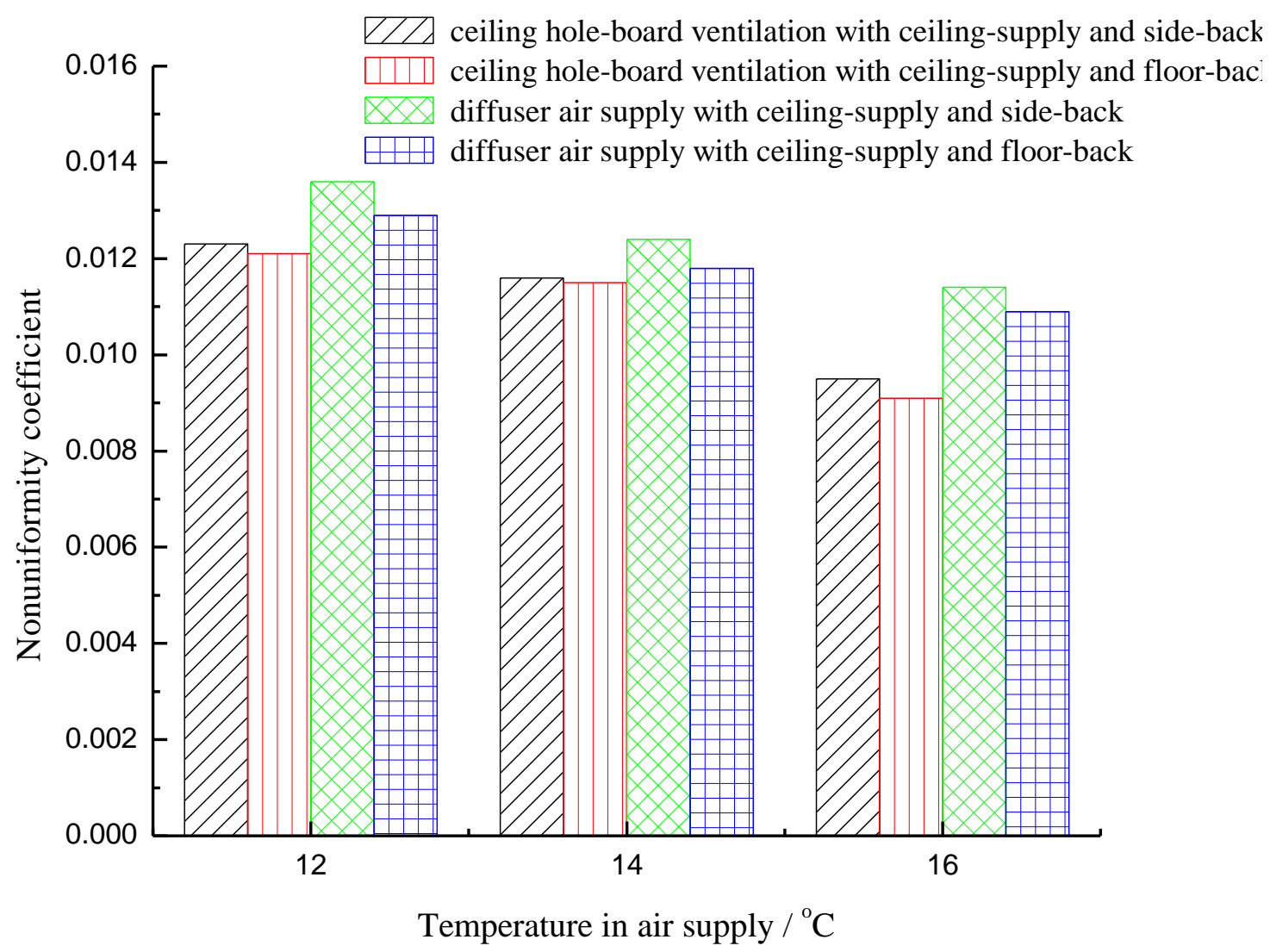

Fig. 9 Nonuniform coefficient with the temperature in air supply in cases 1-4

\section{Conclusions}

In this study, experiments were carried out to research the effects of the air in-back method and the air supply temperature on the temperature field in the air-conditioned room. In conclusions, there are two aspects as following:

[1] In the temperature field uniform experiments, by analyzing the temperature nonuniform coefficient, the method of hole-board ventilation with ceiling air-in and floor air-back can make a more uniformed temperature field. And, with the hole-board ventilation the uniform temperature field had an advantage over the diffuser ventilation. In addition, the more uniformed temperature is obtained with air floor-back method.

[2] In the different air supply temperatures, it is still the hole-board ventilation which can get a more uniformed temperature field. Also, the airflow pattern of the ceiling air-in and floor air-back has a smaller nonuniform coefficient, which means this pattern is suggested in the air conditioning design. Furthermore, with the increasing air supply temperature, the nonuniform coefficient decreases, which shows the temperature field is more uniformed.

\section{References}

[1] Du S.C.,Wang F., \& Wu Z.M. 2005. Development and Analysis of a multifunction man-made Environment Laborator. Refrigeration and Air Conditoning 5(3): 74-77.

[2] Ruan F., Li N.P., \& Li X.H. 2006. Experimental Study on Effects of Inlets and Outlets on Indoor Temperature Field in the Underflor Air Supply System. Refrigeration Air Conditoning \& Electric Power Machinery. 27(4): 30-34. 
[3] Wang F.H., Luo X.L. \& Kong Q.X. 2007. Development And application of an Integrated Experimental Platform of Environmental Room. Research and Exploration in Laboratory 26(3): 36-39.

[4] Xiao F., Shi M., \& Zhang X.P. etal. 2006. Numerical and Experimental Study of the Artificial Simulation Environment Test-chill. Fluid Machinery 34(4): 63-66.

[5] Xiao F., Jin S.M. \& Shi M. 2007. The Study of Air Field in Artificial Environment Laboratory. Refrigeration and Air Conditoning 7(5): 89-92.

[6] Zhou S.J. , Wang Y.F. \& Shu G.A.2008. airflow Numerical Simulation and Optimization of Artificial Simulation Environment Test-chamber. Fluid Machinery 36(4): 73-76. 